\title{
PRIMARY AND SECONDARY LEUCOCYTE CHANGES FOLLOWING THE INTRAMUSCULAR INJECTION OF EPINEPHRINE HYDROCHLORIDE ${ }^{1}$
}

\author{
By A. J. Samuels ${ }^{2}$ \\ (From the Department of Medicine, University of Utah College of Medicine, the Salt Lake \\ General Hospital and the Veterans Administration Hospital, Salt Lake City, Utah)
}

(Submitted for publication April 4, 1951; accepted June 25, 1951)

An increase in the number of circulating leucocytes in human subjects following the parenteral administration of epinephrine has long been known to occur $(1-4)$. Frey $(2,5)$ provided evidence to show that the leucocytes which appear in the circulating blood following administration of epinephrine are delivered, in part, from the spleen. Frey and Hagemann (6) and more recently Doan and Wright (7) have claimed that a significant alteration in the number of circulating formed elements of the blood from that which normally follows the injection of epinephrine reflects the activity of an abnormal spleen.

The test described by Doan and Wright (7) involves the subcutaneous injection of 0.5 to 1.0 mg. of epinephrine hydrochloride. The number of circulating erythrocytes, leucocytes, and thrombocytes, are determined at frequent intervals for a period of one hour, and the maximal change from pre-injection levels is noted. Despite the fact that well-delineated criteria for a positive test are lacking, Doan and Wright ( 7 ) and Kracke and Riser (8) use such response as evidence in favor of the diagnosis of the "hypersplenic syndrome."

More recently a different "epinephrine test," to be used in the evaluation of the functional integrity of the pituitary-adrenocortical system, has been reported (9-11). As described by Recant and associates (9) a small dose (0.3 mg.) of epinephrine hydrochloride is injected subcutaneously in the test subject. The eosinophils are enumerated by absolute count before the injection and four hours later. A decrease of $50 \%$ in the number of circulating eosinophils reflects an intact pituitaryadrenocortical system, and helps to rule out pituitary insufficiency syndromes. The presence of

\footnotetext{
1 Supported in part by research grants from the $\mathrm{Na}$ tional Heart Institute (USPHS) and the Ciba Pharmaceutical Company.

2 Fellow in cardio-vascular research (USPHS).
}

a normal pituitary gland, the functional capacity of the adrenal cortex may be evaluated. Among the clinical syndromes to which the test may be applicable are hypopituitary states (9), Addison's disease $(9,10)$ and situations in which a low adrenal reserve may be a threat to the survival of the patient, as during surgery (11).

In the literature, therefore, two distinctly different "epinephrine tests" are described. The test, as utilized by Doan, is based on the immediate response ("primary phase") of the circulating formed elements to epinephrine, while the late or "secondary phase" following the injection of epinephrine is commonly used to refer to the activity of the pituitary-adrenocortical system. Although the general nature of this biphasic cellular response to epinephrine has been recorded $(2,12$ $15)$, detailed observations on the quantitative alterations of all components of the white cell series are not available. The purpose of this paper is to describe the alterations in the number of circulating leucocytes during both phases of the response to epinephrine in normal human subjects, and to show the relation of the primary phase (the immediate alterations) to the secondary phase (the delayed changes). A preliminary report of this work has appeared (16).

\section{METHODS}

Thirty-four subjects were studied. The patients were reclining, inactive, and fasting throughout the six hour period of the test. The contents of individual ampules, containing $1 \mathrm{ml}$. of a $1: 1000$ aqueous solution of epinephrine hydrochloride, were administered intramuscularly.

Venous blood samples were taken immediately before, and at five, 12, 17, 21 and 30 minutes, and one, two, four and six hours after the injection. A fresh venipuncture was made for each sampling and the blood samples were collected in bottles containing potassium and ammonium oxalate as anticoagulant (17). Cover-slip smears were made from the freshly-drawn specimens and stained with 


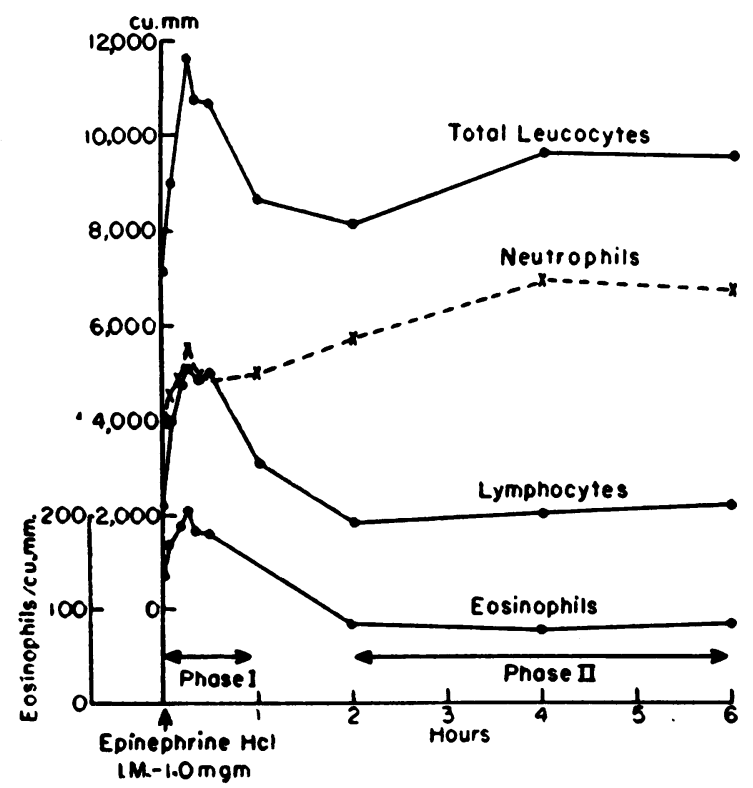

Fig. 1. The Average Change in the Number of Circulating Leucocytes in 20 Normal Human SubJects Following the Intramuscular In Jection of 1.0 ML. OF EPINEPHRINE HYDROCHLORIDE $(1: 1,000)$

The curves are constructed from the average cell counts of all cases, the blood samples having been taken at the same intervals throughout, namely five, 12, 17, 21 and 30 minutes; two, four and six hours after injection.

Wright's stain. The total number of leucocytes was determined in the usual manner from duplicate dilutions. The absolute number of neutrophils and lymphocytes was determined by a count of $200-400$ cells from the stained smears. The absolute number of eosinophils was determined in Levy counting chambers by taking the average count in four dilutions with phloxine propylene glycol diluent (18).

The individuals studied were divided into three groups. Group A consisted of 20 human subjects, including six active and healthy volunteers and 14 hospitalized patients in whom no physical or significant mental illness could be demonstrated. Group B comprised 11 hospitalized patients who had been admitted with various illnesses of a purely medical nature, and who, on recovery, were studied just prior to discharge from the hospital. Group $C$ included three patients in whom a simple but significant inflammatory (neutrophilic) leucocytosis existed at the time of the test. One patient was receiving penicillin therapy for primary lues, one had sustained minor surgery 24 hours before the test, and one patient had an active inflammatory process associated with pyoderma. Control studies following the injection of $1 \mathrm{ml}$. of water were carried out in three subjects to determine whether the procedure of injection and ten to 12 venipunctures produces any significant cell changes.

\section{RESULTS}

A biphasic alteration in the number of eirculating leucocytes followed the injection of epinephrine in all 34 instances (Figure 1). Phase I consisted of a prompt mobilization of all white cell elements, which appeared within five minutes. The maximal effect occurred at 17 minutes, and thereafter subsided toward normal. The average maximal total white cell count was 11,625 per c. $\mathrm{mm}$., an increase of 75 per cent above the average pre-injection count of 6,626 per c. mm. (Table I). The average maximal neutrophil count at the height of the epinephrine effect was 5,550 per c. mm., an increase of 45 per cent above the average baseline neutrophil count of 3,825 per c. mm. The average lymphocyte count at the maximal point was 5,175 per c. mm., an increase of 130 per cent above the control value of 2,250 per c. $\mathrm{mm}$. The average number of circulating eosinophils, at the height of the effect of the stimulus, was 203 per c. mm., an increase of 45 per cent above the preinjection average count of 138 per c. mm. It will

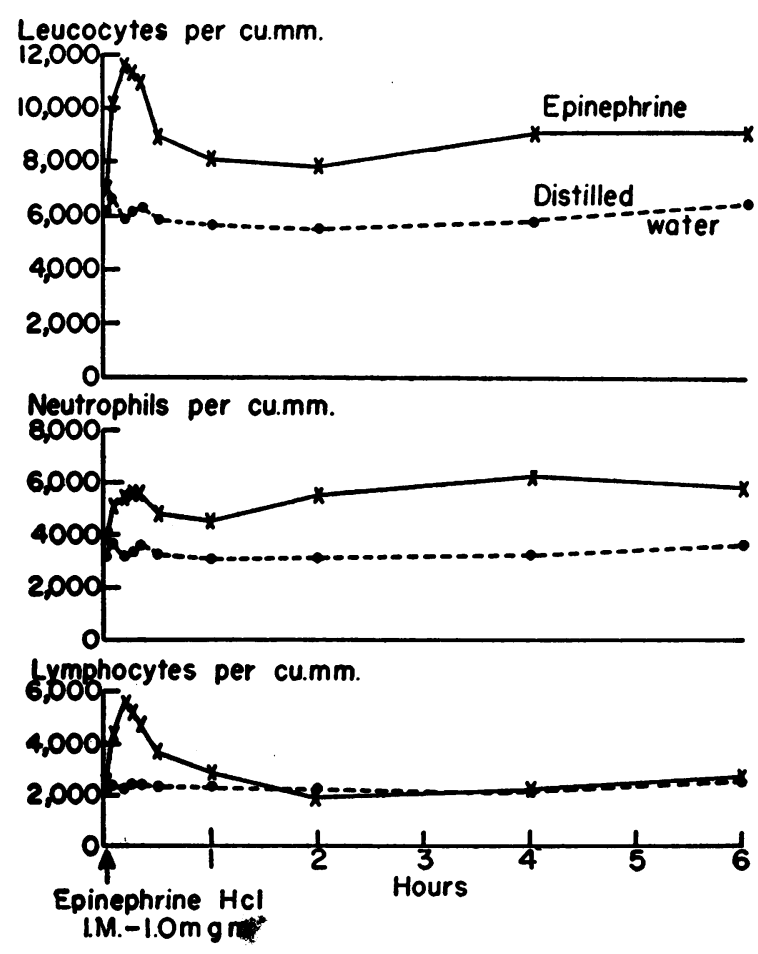

Fig. 2. The Influence of Epinephrine Hydrochloride Compared with Distilled Water on Circulating Leucocytes in the Same Three Normal Human Subjects 
TABLE I

The mean leucocyte count at rest in 20 normal human subjects and the change in cell count following the intramuscular injection of epinephrine (Group $A$ )

\begin{tabular}{|c|c|c|c|c|c|c|}
\hline Cells & Phase & $\underset{\text { per c.mm. }}{\text { Mean count }}$ & Standard & Range & $\underset{\text { per cent }}{\text { Mean change }}$ & $\mathbf{P}^{*}$ \\
\hline \multirow{3}{*}{$\begin{array}{c}\text { Total } \\
\text { leucocytes }\end{array}$} & Control & 6,625 & \pm 250 & $\begin{array}{l}4,300 \\
8,900\end{array}$ & & \\
\hline & I-(17 min.) & 11,625 & \pm 700 & $\begin{array}{r}6,420 \\
17,000\end{array}$ & +75.5 & $<0.001$ \\
\hline & II-(4 hours) & 9,700 & \pm 475 & $\begin{array}{r}5,820 \\
14,825\end{array}$ & +46.4 & $<0.001$ \\
\hline \multirow{3}{*}{ Neutrophils } & Control & 3,825 & \pm 200 & $\begin{array}{l}1,975 \\
5,075\end{array}$ & & \\
\hline & I- $(17 \mathrm{~min})$. & 5,550 & \pm 425 & $\begin{array}{l}2,250 \\
9,350\end{array}$ & +44.8 & $<0.001$ \\
\hline & II-(4 hours) & 7,075 & \pm 375 & $\begin{array}{r}4,365 \\
10,800\end{array}$ & +84.9 & $<0.001$ \\
\hline \multirow{3}{*}{ Lymphocytes } & Control & 2,250 & \pm 150 & $\begin{array}{l}1,400 \\
3,350\end{array}$ & & \\
\hline & I- $(17 \mathrm{~min})$. & 5,175 & \pm 375 & $\begin{array}{l}2,750 \\
8,000\end{array}$ & +130.0 & $<0.001$ \\
\hline & II-(2 hours) & 1,925 & \pm 125 & $\begin{array}{l}1,150 \\
3,650\end{array}$ & -14.9 & $<.01$ \\
\hline \multirow{3}{*}{ Eosinophils } & Control & 138 & \pm 10 & $\begin{array}{r}47 \\
285\end{array}$ & & \\
\hline & $\mathrm{I}-(17 \mathrm{~min})$. & 203 & \pm 20 & $\begin{array}{r}68 \\
444\end{array}$ & +47.0 & $<0.001$ \\
\hline & II-(4 hours) & 80 & \pm 5 & $\begin{array}{r}30 \\
153\end{array}$ & -42.1 & $<0.001$ \\
\hline
\end{tabular}

* $\mathrm{P}$-The probability that the given per cent change is not different from a mean change of zero. The probability that the change is statistically significant is therefore high in every instance.

be seen in Table I that all changes are highly significant, $P$ values being less than 0.01 in all instances.

There was a tendency for the number of circulating lymphocytes to equal the number of neutrophils at the height of the effect in Phase I, despite the fact that normally the absolute number of lymphocytes is less than two-thirds of the resting neutrophil count $(\mathrm{L}-2,250, \mathrm{~N}-3,825)$. The degree of change in the lymphocytes was, therefore, greater than observed in the other white cell elements. The lymphocytes in Phase I were usually mobilized at the same time as were neutrophils although, in several instances, the lymphocytosis preceded the neutrophilia. It is noteworthy that the eosinophils, although small in absolute numbers, were increased significantly in the first phase following the injection of epinephrine.
The changes related to Phase II (Figure 1) became apparent within two hours after the administration of epinephrine. At this time the lymphocytes were observed to be maximally altered from control levels by a decrease of 15 per cent (Table I). Changes in the number of circulating neutrophils were maximal at four hours, at which time an increase of 85 per cent above control values was recorded. It is obvious that the secondary elevation of the neutrophil count is responsible for the overall 46 per cent increase in the total white cell count observed at four hours. Eosinophil changes were characterized by a decrease of 42 per cent below pre-injection values, the maximal effect also occurring at four hours.

As illustrated in Figure 2 the injection of $1.0 \mathrm{ml}$. of distilled water followed by repeated venipuncture failed to cause significant alterations in the 
number of circulating leucocytes throughout a six hour period of observation. The administration of epinephrine to the same three individuals was followed by the characteristic biphasic leucocyte response.

Eleven patients (Group B) who were hospitalized for a variety of medical illnesses (Table II) were "epinephrine-tested" just prior to discharge from hospital. The cellular response to epinephrine was the same as in Group A except that in this group the neutrophilia expected during Phase II was significantly less, an average increase of 54 per cent being recorded as compared with 85 per cent in the normal subjects. A manifestation of the same phenomenon, but to an even greater degree, was observed in three patients (Group C) who, at the time of the test, had a leucocytosis associated with acute inflammation. In all three instances in Group C, (Table II) the number of circulating neutrophils, at the height of the effect in Phase II, was found to be actually reduced below pre-injection levels $(-27$ per cent) rather than having reached the expected 85 per cent increase. The difference between the three groups, in regard to the secondary neutrophilic response is statistically highly significant (Table III).

\section{DISCUSSION}

In normal human subjects all components of the circulating white cell series are mobilized in the "primary phase" (Phase I) of the epinephrine test. This observation is clinically significant inasmuch as a similar change in circulating leucocytes is implied by some authors $(7,8)$ to represent the degree of sequestering activity of the spleen. It is further implied by those authors that an increase beyond the normal degree of response in the mobilization of circulating leucocytes following epinephrine administration would reflect an increased, pathologic sequestering activity of a hyperactive spleen.

Admittedly the clinically enlarged spleen does commonly decrease in size following parenteral administration of epinephrine concomitantly with

TABLE II

Maximal per cent change in the number of circulating leucocytes occurring within Phase I and Phase II after the intramuscular injection of epinephrine in patients hospitalized for various medical illnesses (Group B) and in patients with inflammatory leucocytosis (Group C)

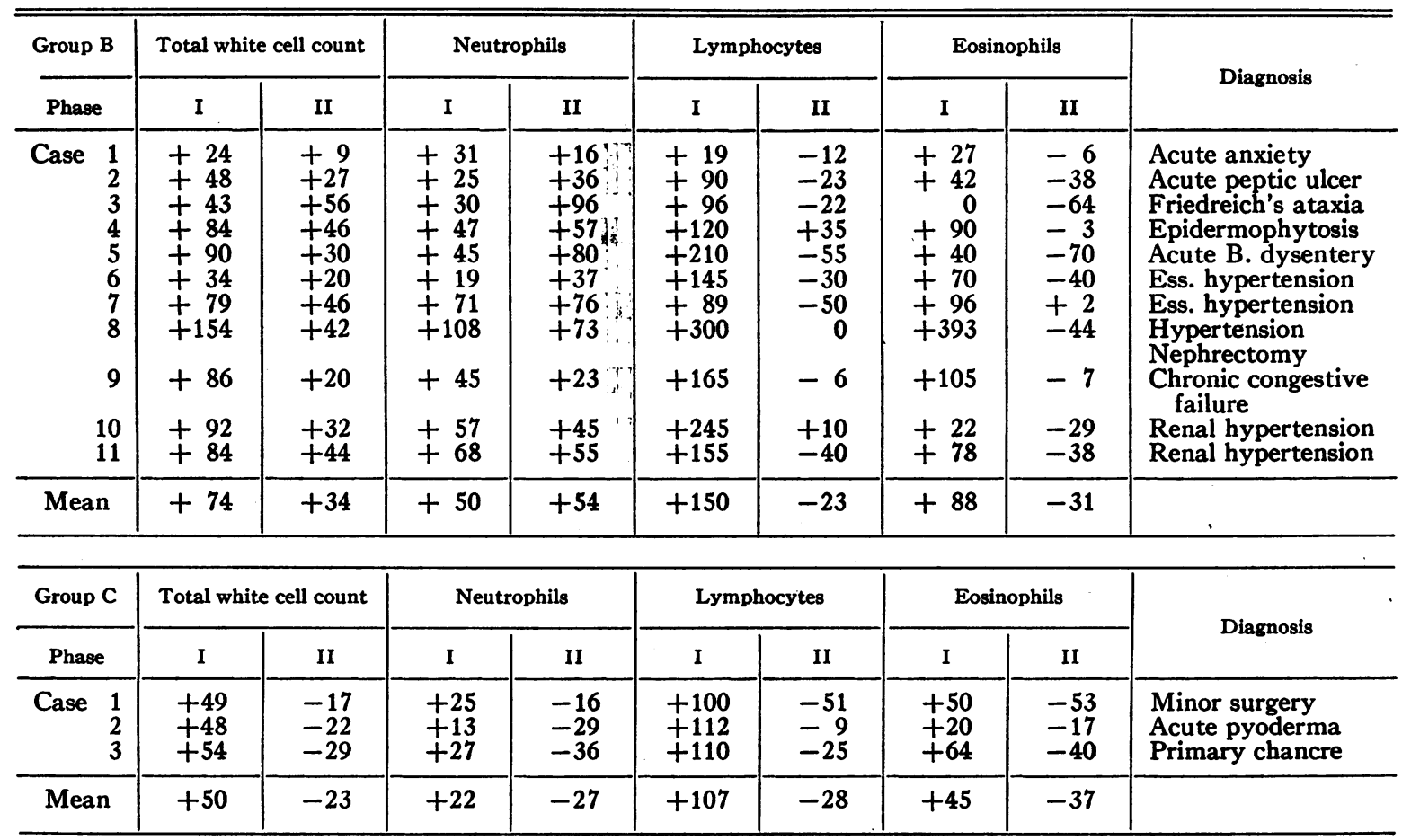


TABLE III

The mean maximal per cent change in the number of circulating leucocytes occurring within Phase I and Phase II after the intramuscular injection of epinephrine hydrochloride in hospital patients

\begin{tabular}{c|c|c|c|c|c|c|c|c|c}
\hline \hline \multirow{2}{*}{ Group } & \multirow{2}{*}{ No. } & \multicolumn{2}{|c|}{ Total white count } & \multicolumn{2}{|c|}{ Neutrophils } & \multicolumn{2}{|c|}{ Lymphocytes } & \multicolumn{2}{|c}{ Eosinophils } \\
\cline { 2 - 9 } & & Phase I & Phase II & Phase I & . Phase II & Phase I & Phase II & Phase I & Phase II \\
\hline $\mathrm{A}^{*}$ & 20 & +89 & +60 & +59 & +108 & +166 & -16 & +77 & -46 \\
\hline $\mathrm{B} \dagger$ & 11 & +74 & +34 & +50 & +54 & +150 & -23 & +88 & -31 \\
\hline $\mathrm{C} \ddagger$ & 3 & +50 & -23 & +22 & -27 & +107 & -28 & +45 & -37 \\
\hline PB \& & & & & & $<0.01$ & & & & \\
PC\| & & & & & $>0.05$ & & & & \\
\hline
\end{tabular}

* Group A-Normal human subjects.

† Group B-Patients hospitalized for various acute and chronic illnesses.

F Group C-Patients with acute inflammatory neutrophilic leucocytosis.

PB-The difference in the response of neutrophils of Group B in Phase II as compared with Group A is highly significant.

II PC-The difference in the response of neutrophils of Group C in Phase II as compared with Group B is significant. Compared with Group $\mathrm{A}$ then the difference is highly significant.

the increase in circulating leucocytes (19). It appears, however, that complex mechanisms other than splenic contraction are involved in Phase I leucocyte changes (20).

From these observations concerning Phase $I$ it may be concluded that the application of the epinephrine test in the recognition of "hypersplenic" states requires consideration of the degree of response in normal human subjects. A comparison between the response in normal subjects and patients with hematologic changes characteristic of the "hypersplenic" syndromes is at present in preparation.

Michael (13), in an extensive review has recently considered the biphasic alterations in the circulating leucocytes which follow the administration of epinephrine. He has suggested that a hormonal influence of the pituitary-adrenocortical system may be involved in the primary changes in circulating leucocytes which follow the injection of epinephrine. It is of interest that the administration of $\mathrm{ACTH}^{3}$ to two subjects in this laboratory failed to evoke significant primary changes in either instance.

Hormonal factors do seem concerned, however, in the leucocyte changes of Phase II. That an in-

${ }^{3}$ ACTH-A single intramuscular injection of ACTH, equivalent in potency to $25 \mathrm{mg}$. of the Armour Standard La-1-A, supplied through the courtesy of Dr. J. R. Mote, Armour Laboratories, Chicago, Ill. crease in circulating neutrophils, together with a decrease in lymphocytes and eosinophils, reflects an increased adrenal cortical secretion is well documented $(9,21,22)$. Identical changes follow the injection of ACTH in both animals and man. These leucocyte changes, therefore, reflect augmented activity of the intact pituitary-adrenocortical system.

It has been previously demonstrated that the administration of epinephrine in normal human subjects also elicits the general leucocyte changes characteristic of Phase II herein described $(9,12)$. In experimental animals the removal of the anterior pituitary gland or the adrenal cortex, however, vitiates the secondary lymphopenia and eosinopenic response to epinephrine (9). In human subjects during states of hypoadrenal activity, the secondary eosinopenic response to epinephrine has been shown to be absent (11).

Neutrophils, on the other hand, demonstrate a quite dissimilar behavior. Dougherty and White (21) clearly demonstrated that despite removal of the adrenal cortex in experimental animals, an increase in circulating neutrophils nonetheless followed the administration of ACTH. In these instances the lymphopenia did not appear. Hills, Forsham and Finch (23) described a similar although submaximal neutrophilia following the administration of ACTH in patients with Addison's disease. During these tests lymphopenia and 
eosinopenia did not occur. More recently Hungerford (24) has reported that despite simultaneous hypophysectomy and adrenalectomy in rats, the injection of adrenalin is followed by a significant increase in the number of circulating neutrophils at four hours.

It therefore appears that the presence of the anterior pituitary gland or adrenal cortex is not essential for the secondary neutrophilic response to epinephrine and ACTH, unlike the behavior of lymphocytes and eosinophils. Factors which influence the number of circulating neutrophils are not therefore identical with those responsible for changes in circulating lymphocytes and eosinophils. This is in keeping with our observation of an unexpected decrease in circulating neutrophils in Phase II despite the normal lymphopenic and eosinopenic response to epinephrine in the patients with inflammatory leucocytosis (Group C).

The injection of epinephrine in normal human subjects is thus characterized by a biphasic alteration in the number of circulating leucocytes. The primary phase involves a mobilization of at least neutrophils, lymphocytes and eosinophils. In an analysis of secondary changes the early primary alterations may certainly influence the degree of response in the later phase. It would seem, therefore, that frequent sampling of blood is necessary to delineate the quality and quantity of leucocyte changes in both phases of the epinephrine test.

\section{SUM MARY}

1. Epinephrine $(1.0 \mathrm{mg}$.) was administered intramuscularly to 34 human subjects. A biphasic alteration in the number of circulating leucocytes was observed.

2. In Phase I a prompt mobilization of all white cell elements appeared within five minutes, the effect became maximal at 17 minutes, and thereafter returned toward normal. The total white cell count increased 75 per cent, the neutrophils increased 45 per cent, the lymphocytes 130 per cent, and the eosinophils 47 per cent at the time of maximum change.

3. The second phase consisted of a secondary rise in the total white cell count of 46 per cent, an 85 per cent increase in circulating neutrophils, a 15 per cent reduction in lymphocytes and a 42 per cent decrease in eosinophils. The maximal effect on the lymphocytes was apparent at two hours after injection, while the changes in total white cell count, neutrophils and eosinophils were maximal at the four hour sampling.

4. In three patients with a neutrophilic leucocytosis associated with acute inflammation there was a reduction $(-27$ per cent $)$ in the number of circulating neutrophils at four hours after the injection of epinephrine.

5. The mechanisms involved in both phases and the limitations in the clinical application of the epinephrine test are discussed briefly.

\section{ACKNOWLEDGMENTS}

I desire to express my appreciation to Doctors Hans H. Hecht, George E. Cartwright and Frank H. Tyler, for their constant interest and stimulation and for their suggestions as this study progressed. My thanks are also due to Mr. Robert Carlisle for his technical assistance.

\section{REFERENCES}

1. Loeper, M., and Crouzon, D., Arch d. méd. exper., $1904,16,83$, quoted in Lucia, S. P., Leonard, M. E., and Falconer, E. H., The effect of the subcutaneous injection of adrenalin on the leukocyte count of splenectomized patients and of patients with certain diseases of the hematopoietic and lymphatic systems. Am. J. M. Sc., 1937, 194, 35.

2. Frey, W., and Lury, S., Adrenalin zur funktionellen Diagnostik der Milz: Untersuchengen an klinischem Material. Ztschr. f. d. ges. exper. Med., 1914, 2, 50.

3. Garrey, W. E., and Bryan, W. R., Variations in white blood cell counts. Physiol. Rev., 1935, 15, 597.

4. Hortling, H., The influence of electric shock and adrenalin injections on the leukopoiesis and erythropoiesis; contribution to the problem of neurovegetative regulation of hematopoiesis. Acta med. Scandinav., 1947, Suppl., 201.

5. Frey, W., Der Einfluss des vegetativen Nervensystems auf das Blutbild. Ztschr. f. d. ges. exper. Med., 1914, 2, 38.

6. Frey, W., and Hagemann, E., Die Brauchbarkeit der adrenalinlymphozytose zur Funktionsprüfung der Milz. Klinisches und experimentelles Beweismaterial. Ztschr. f. klin. Med., 1921, 92, 450.

7. Doan, C. A., and Wright, C. S., Primary congenital and secondary acquired splenic panhematopenia. Blood, 1946, 1, 10.

8. Kracke, R. R., and Riser, W. H., Jr., The problem of hypersplenism. J.A.M.A., 1949, 141, 1132.

9. Recant, L., Hume, D. M., Forsham, P. H., and Thorn, G. W., Studies on the effect of epinephrine on the pituitary-adrenocortical system. J. Clin. Endocrinol., 1950, 10, 187. 
10. Thorn, G. W., Bayles, T. B., Massell, B. F., Forsham, P. H., Hill, S. R., Jr., Smith, S., and Warren, J. W., Studies on the relation of pituitary-adrenal function to rheumatic disease. New England J. Med., 1949, 241, 529.

11. Roche, M., Thorn, G. W., and Hills, A. G., The levels of circulating eosinophils and their response to ACTH in surgery; their use as index of adrenocortical function. New England J. Med., 1950, 242, 307.

12. Hatiegan, J., Untersuchungen über die Adrenalinwirkung auf die weissen Blutzellen, Wien. klin. Wchnschr., 1917, 30, 1541.

13. Michael, S. T., Adaptation to brief stress; blood level of leucocytes and adrenal function in epilepsy, electrically induced convulsions, and after injection of epinephrine; review and interpretation. Yale J. Biol. \& Med., 1949, 22, 71.

14. Gabrilove, J. L., Volterra, M., Jacobs, M. D., and Soffer, L. J., The effect of the parenteral injection of epinephrine on leucocyte counts in normal subjects and in patients with Addison's disease. Blood, 1949, 4, 646.

15. White, C., Ling, T. H., and Klein, A. M., The effect of administration of epinephrine on the leucocyte counts of normal subjects. Blood, 1950, 5, 723.

16. Samuels, A. J., Hecht, H. H., Tyler, F., and Carlisle, $R$., Leucocyte changes following the intramuscular injection of epinephrine and epinephrine congeners, with observations on the alterations induced by adrenergic blocking agents. Am. J. Med., 1950, 8, 533.

17. Wintrobe, M. M., Clinical Hematology. Lea \& Febiger, Philadelphia, 1946, ed. 2, p. 241.

18. Randolph, T. G., Blood studies in allergy. I. The direct counting chamber determination of eosinophils in propylene glycol aqueous stains. J. Allergy, 1944, 15, 89.

19. Personal observations.

20. Samuels, A. J., Hecht, H. H., Tyler, F., and Carlisle, $R$., The influence of adrenergic blocking agents on the primary leucocyte changes which follow the injection of epinephrine and epinephrine congeners in human subjects. In preparation.

21. Dougherty, T. F., and White, A., Influence of adrenal cortical secretion on blood elements. Science, 1943, 98, 367.

22. Reinhardt, W. O., Aron, H., and Li, C. H., Effect of adrenocorticotropic hormone on the leucocyte picture of normal rats and dogs. Proc. Soc. Exper. Biol. \& Med., 1944, 57, 19.

23. Hills, A. G., Forsham, P. H., and Finch, C. A., Changes in circulating leucocytes induced by the administration of pituitary adrenocorticotrophic hormone (ACTH) in man. Blood, 1948, 3, 755.

24. Hungerford, G. F., Effect of epinephrine in decreasing number of circulating mononuclear leucocytes in the rat. Proc. Soc. Exper. Biol. \& Med., 1949, 70, 356. 